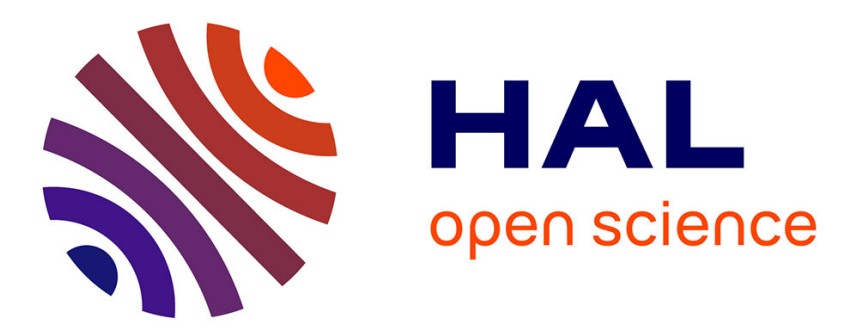

\title{
Monitoring in situ the colloidal synthesis of AuRh/TiO 2 selective-hydrogenation nanocatalysts
}

\author{
Zere Konuspayeva, Gilles Berhault, Pavel Afanasiev, Thanh-Son Nguyen, \\ Suzanne Giorgio, Laurent Piccolo
}

\section{- To cite this version:}

Zere Konuspayeva, Gilles Berhault, Pavel Afanasiev, Thanh-Son Nguyen, Suzanne Giorgio, et al.. Monitoring in situ the colloidal synthesis of $\mathrm{AuRh} / \mathrm{TiO} 2$ selective-hydrogenation nanocatalysts. Journal of Materials Chemistry A, 2017, 5 (33), pp.17360 - 17367. 10.1039/c7ta03965d . hal-01610388

\section{HAL Id: hal-01610388 \\ https://hal-amu.archives-ouvertes.fr/hal-01610388}

Submitted on 6 Feb 2018

HAL is a multi-disciplinary open access archive for the deposit and dissemination of scientific research documents, whether they are published or not. The documents may come from teaching and research institutions in France or abroad, or from public or private research centers.
L'archive ouverte pluridisciplinaire HAL, est destinée au dépôt et à la diffusion de documents scientifiques de niveau recherche, publiés ou non, émanant des établissements d'enseignement et de recherche français ou étrangers, des laboratoires publics ou privés. 


\title{
Monitoring in situ the colloidal synthesis of AuRh/ $\mathrm{TiO}_{2}$ selective-hydrogenation nanocatalysts
}

\author{
Zere Konuspayeva, ${ }^{a}$ Gilles Berhault, ${ }^{a}$ Pavel Afanasiev, ${ }^{a}$ Thanh-Son Nguyen, ${ }^{a}$ \\ Suzanne Giorgio ${ }^{\mathrm{b}}$ and Laurent Piccolo (iD *a
}

\begin{abstract}
AuRh nanoparticles (NPs) of various compositions and sizes in the 2-4 $\mathrm{nm}$ range were synthesized using a colloidal approach and were characterized at each preparation step by dynamic light scattering (DLS), ultraviolet-visible (UV-vis) spectroscopy, and liquid-phase transmission electron microscopy (liquid TEM). The AuRh colloids appear relatively instable, leading to their gradual coalescence. After fast immobilization of the metallic nanoparticles on rutile $\mathrm{TiO}_{2}$ nanorods, the materials were investigated by high-resolution transmission electron microscopy (HRTEM) and low-temperature CO adsorption monitored by Fourier transform infrared (FTIR) spectroscopy. The inherent lack of miscibility between $\mathrm{Au}$ and Rh leads to partial segregation inside the NPs, which is further exalted after a reducing thermal treatment applied for PVA removal. The catalytic properties in the liquid-phase selective hydrogenation of cinnamaldehyde to hydrocinnamaldehyde are strongly influenced by these nanostructural modifications. While in as-prepared samples the intermixing between Au and Rh phases promotes the catalytic performances for Rh-rich AuRh catalysts through Au-induced stabilization of Rh in its metallic form, segregation into Janus particles after reduction decreases the catalytic activity.
\end{abstract}

\section{Introduction}

Bimetallic nanoparticles are of prominent importance in heterogeneous catalysis since the choices of metals and compositions allow one to tune the catalyst selectivity and improve its activity and stability. ${ }^{1}$ Among the noble bimetallic catalysts, AuPd has been the most extensively studied system due both to the miscibility of $\mathrm{Au}$ and $\mathrm{Pd}$ for all compositions, ensuring formation of a homogeneous alloy structure, and to strong synergetic effects observed in numerous catalytic applications. ${ }^{2}$ On the opposite, the AuRh system has only been rarely investigated. Indeed, $\mathrm{Au}$ and $\mathrm{Rh}$ show large differences in cohesion and surface energies and a large lattice mismatch resulting in a broad miscibility gap in the bulk AuRh phase diagram. ${ }^{3}$ However, some attempts have been made to prepare AuRh NPs with controlled composition and structure. Extensive work on this system was performed by Kiss, Óvári and coworkers. ${ }^{4-7}$ Using either chemical or physical preparation techniques, they showed that $\mathrm{Au}$ tends to cover the $\mathrm{Rh}$ surface. Using scanning transmission electron microscopy (STEM), Chantry et al. ${ }^{\mathbf{8} 9}$ highlighted the tendency of Rh either to deposit in an uneven way on Au nanorods and/or to form mixed alloy layers at the topmost surface depending on kinetic issues

a'Univ Lyon, Université Claude Bernard - Lyon 1, CNRS, IRCELYON - UMR 5256, 2 Avenue Albert Einstein, F-69626 Villeurbanne Cedex, France. E-mail: laurent. piccolo@ircelyon.univ-lyon1.fr

${ }^{b}$ Aix-Marseille Université, CNRS, Centre Interdisciplinaire de Nanoscience de Marseille, UMR 7325, 13288 Marseille, France during the formation of such nanostructures. Similarly, Sneed et al. ${ }^{\mathbf{1 0}}$ observed the formation of island overgrowth of $\mathrm{Rh}$ onto Au nanocubes or octahedra. Using microwave irradiation, Garcia et $a .^{\mathbf{1 1}}$ synthesized AuRh NPs stabilized by PVP (polyvinylpyrrolidone) and deposited on amorphous silica, which exhibited a slight enhancement of activity in cyclohexene hydrogenation as compared to Rh NPs. Essinger-Hileman et $a .^{12}$ synthesized AuRh solid-solution alloy NPs, though for very low amounts of metal precursors. Recently, Shubin et al. successfully prepared metastable AuRh solid solutions from the thermal decomposition of home-made bimetallic precursors. ${ }^{13}$

In spite of the high hydrogenation performance of $\mathrm{Rh}$ and the promoting capability of $\mathrm{Au},{ }^{3}$ selective hydrogenation applications have been rarely envisaged up to now for AuRh bimetallic systems, limiting our knowledge of structure/performance relationships. The selective hydrogenation of cinnamaldehyde (CALD) ${ }^{14-16}$ to hydrocinnamaldehyde (HCALD) is of interest for flavor and fragrance industries. ${ }^{17}$ Moreover, the reaction is structure-sensitive, as its performance depends on the type of exposed crystallographic planes, ${ }^{18-21}$ the nature and size of the metallic NPs, ${ }^{17,19,22-26}$ and the nature of the support. ${ }^{22,23}$ Some studies have shown the interest of using $\mathrm{TiO}_{2}$ as a support for modifying the activity and the selectivity of Au NPs. ${ }^{27}$ Goldbased bimetallic NPs considered up to now for this reaction are AuPd, ${ }^{28,29} \mathrm{AuCu},{ }^{30}$ and $\mathrm{AuNi}{ }^{31}$ systems.

We have previously reported on the colloidal preparation and characterization of AuRh NPs immobilized on rutile titania nanorods. ${ }^{3,32}$ The model catalysts were evaluated for the 
hydrogenation of tetralin in the presence of $\mathrm{H}_{2} \mathrm{~S}^{3}$ and the hydrodeoxygenation (HDO) of guaiacol, ${ }^{33}$ both reactions being performed in the gas phase. In both cases, the bimetallic combination proved to behave differently from the $\mathrm{Au}$ and $\mathrm{Rh}$ counterparts, and the catalytic performance was improved by $\mathrm{Au}-\mathrm{Rh}$ nanoalloying. It was also shown that calcinationreduction and direct reduction treatments are able to remove the PVA surfactant for activating the catalysts. However, the former treatment leads to metal phase separation into monometallic particles, while the direct reduction leads to phase segregation inside the bimetallic particles. ${ }^{3}$ In the latter case, an $\mathrm{Au} / \mathrm{Rh} / \mathrm{TiO}_{2}$ stacked structure was evidenced, and further STEM characterization and modeling allowed us to explain this chemical arrangement by the lower surface and cohesion energies of $\mathrm{Au}$ with respect to $\mathrm{Rh}$, and the preferential binding of Rh with the titania support. ${ }^{34-36}$

Here, we report on the nucleation and growth of AuRh NPs directly characterized in solution, the surface characteristics of the corresponding as-prepared or treated titania-supported catalysts, and their performance in liquid-phase selective hydrogenation of cinnamaldehyde. In particular, this study is focused on the relationship between the catalytic properties of the supported NPs and their chemical structure, which is itself influenced by the pretreatment.

\section{Experimental section}

\section{Materials synthesis methods}

$\mathrm{TiO}_{2}$ rutile nanorods were prepared using a simplified procedure based on a hydrothermal method reported by Li and Afanasiev. ${ }^{37} 10 \mathrm{~g}$ of Degussa P25 $\mathrm{TiO}_{2}\left(50 \mathrm{~m}^{2} \mathrm{~g}^{-1}\right)$ and $100 \mathrm{~mL}$ of $15 \mathrm{wt} \% \mathrm{H}_{2} \mathrm{SO}_{4}$ solution were mixed in a Teflon reactor and placed in a sealed autoclave kept at $200{ }^{\circ} \mathrm{C}$ for 15 days. The obtained solid was washed several times with $0.1 \mathrm{M} \mathrm{NH}_{4} \mathrm{NO}_{3}$ to remove adsorbed sulfate, then washed with distilled water, dried at $100{ }^{\circ} \mathrm{C}$ overnight, and calcined at $350{ }^{\circ} \mathrm{C}$ in air for $2 \mathrm{~h}$.

AuRh NPs, along with their monometallic counterparts, were prepared using a colloidal (co)reduction route. The metal precursors were $\mathrm{HAuCl}_{4} \cdot 3 \mathrm{H}_{2} \mathrm{O}$ (Strem Chemicals, 99.9\%, $49 \mathrm{wt} \% \mathrm{Au}$ ) and $\mathrm{RhCl}_{3} \cdot n \mathrm{H}_{2} \mathrm{O}$ (Sigma-Aldrich, 99.9\%, 38-40 wt\% Rh). In a first step, a $200 \mathrm{~mL}$ aqueous solution containing the two metallic precursors was prepared by adding the amounts of precursors necessary for reaching a total metal loading of $3 \mathrm{wt} \%$. Next, a $1 \mathrm{wt} \%$ aqueous solution of polyvinyl alcohol (PVA, $M_{\mathrm{w}}=10000$ ) was added to the preceding solution while maintaining a mass ratio $m_{\mathrm{PVA}} / m_{\mathrm{Au}+\mathrm{Rh}}$ of 1.2 . A solution of $0.1 \mathrm{M}$ $\mathrm{NaBH}_{4}$, freshly prepared and kept at $0{ }^{\circ} \mathrm{C}$ before use, was then dropped under stirring in the solution of metallic precursors with a molar ratio $n_{\mathrm{NaBH} 4} / n_{\mathrm{Au}+\mathrm{Rh}}$ of 5 to ensure a complete reduction of the two metals. Immediately after $\mathrm{NaBH}_{4}$ addition, the color of the solution changed from yellowish orange to black, indicating the reduction of $\mathrm{Au}^{3+}$ and $\mathrm{Rh}^{3+}$ ions into $\mathrm{Au}^{0}$ and $\mathrm{Rh}^{0}$. Stirring was then maintained for $30 \mathrm{~min}$ to allow the complete decomposition of the exceeding $\mathrm{NaBH}_{4}$. The solution was then acidified to $\mathrm{pH} 3.5$ by addition of $\mathrm{HCl} 0.01 \mathrm{M}$ in order to favor the sol immobilization onto the $\mathrm{TiO}_{2}$ support. The amount of support necessary for reaching the final metal loading was then added and stirring was kept for $3 \mathrm{~h}$. Finally, the material was filtrated, washed with hot distilled water $\left(70{ }^{\circ} \mathrm{C}\right)$ several times, and dried at $100{ }^{\circ} \mathrm{C}$ overnight. In some cases, a reductive post-treatment was performed by heating the samples to $350{ }^{\circ} \mathrm{C}\left(10^{\circ} \mathrm{C} \min ^{-1}, 3 \mathrm{~h}\right.$ plateau $)$ in hydrogen flow ( $\left.5 \mathrm{~mL} \min ^{-1}, 1 \mathrm{~atm}\right)$. Table 1 reports the series of synthesized catalysts.

\section{Materials characterization methods}

The metal loadings were determined by inductively coupled plasma optical emission spectroscopy (ICP-OES, Horiba Jobin Yvon Activa). Before analysis, the samples were treated with a mixture of $\mathrm{H}_{2} \mathrm{SO}_{4}$, aqua regia, and $\mathrm{HF}$ at $250-300{ }^{\circ} \mathrm{C}$. Dynamic light scattering (DLS) experiments were performed on a Wyatt DynaPro NanoStar equipment using a $658 \mathrm{~nm}$ laser wavelength and a $90^{\circ}$ scattering angle for detection. Au and $\mathrm{Rh}$ colloidal solutions were analyzed every $20 \mathrm{~min}$ with a $5 \mathrm{~s}$ acquisition time while the evolution of AuRh NPs in solution was determined by recording data every $30 \mathrm{~min}$ with the same acquisition time. The Dynamics software was used to acquire the data. UV-vis spectra of the PVA-stabilized $\mathrm{Au}, \mathrm{Rh}$, and AuRh colloidal suspensions were recorded on a Lambda 35 (Perkin Elmer) spectrometer in the 190-1100 $\mathrm{nm}$ wavelength region at $1 \mathrm{~nm} \mathrm{~min}^{-1}$ acquisition rate. Transmission electron microscopy (TEM) was performed using an aberration-corrected FEI Titan ETEM G2 operated at $300 \mathrm{kV}$ (CLYM). For TEM sample preparation, the catalysts were crushed in ethanol and the solution was ultrasonically stirred before dropping it on a holey carbon-covered copper TEM grid, followed by drying. For liquid-phase TEM experiments, an aqueous solution containing the $\mathrm{Au}$ and $\mathrm{Rh}$ precursors and the PVA surfactant was encapsulated between two graphene oxide layers on a carbon film deposited onto a copper grid before being observed with a Jeol 3010 TEM operating at $300 \mathrm{kV} .^{38}$ During the observation at a constant magnification of $10^{5}$, the current density was stabilized at about $150 \mathrm{pA} \mathrm{cm}^{-2}$ at the screen level. During the reduction in the electron beam, the nucleation and growth of AuRh NPs was followed in real time in a selected area for a few minutes. In this work, the selected images were recorded before the solvent evaporation, so that the metal concentration in the observed area was constant. Transmission infrared spectroscopy of adsorbed CO (CO-FTIR) was carried out using a Thermo Nicolet 6700 spectrometer (DTGS detector) combined with a custom-made glass cell ${ }^{3}$

Table 1 Characteristics of the supported catalysts

\begin{tabular}{|c|c|c|c|c|}
\hline \multirow[b]{2}{*}{ Catalyst } & \multicolumn{2}{|c|}{$\mathrm{Au}: \mathrm{Rh}$ atomic ratio ${ }^{a}$} & \multirow{2}{*}{$\begin{array}{l}\text { Metal } \\
\text { loading }^{a} \\
(\mathrm{wt} \%)\end{array}$} & \multirow{2}{*}{$\begin{array}{l}\text { Particle size } \\
(\mathrm{nm})\end{array}$} \\
\hline & Targeted & Measured & & \\
\hline $\mathrm{Rh} / \mathrm{TiO}_{2}$ & $0: 100$ & - & 0.6 & $2.4 \pm 0.6$ \\
\hline $\mathrm{Au}_{13} \mathrm{Rh}_{87} / \mathrm{TiO}_{2}$ & $10: 90$ & $13: 87$ & 2.2 & $2.4 \pm 0.9$ \\
\hline $\mathrm{Au}_{37} \mathrm{Rh}_{63} / \mathrm{TiO}_{2}$ & $30: 70$ & $37: 63$ & 2.4 & $3.2 \pm 1.2$ \\
\hline $\mathrm{Au}_{57} \mathrm{Rh}_{43} / \mathrm{TiO}_{2}$ & $50: 50$ & $57: 43$ & 2.2 & $4.0 \pm 1.3$ \\
\hline $\mathrm{Au}_{63} \mathrm{Rh}_{37} / \mathrm{TiO}_{2}$ & $60: 40$ & $63: 37$ & 2.5 & $3.3 \pm 1.0$ \\
\hline $\mathrm{Au} / \mathrm{TiO}_{2}$ & $100: 0$ & - & 1.5 & $2.8 \pm 0.8$ \\
\hline
\end{tabular}

${ }^{a}$ Determined by ICP-OES. ${ }^{b}$ Determined by TEM. 
which allows for in situ treatment (gas flow, $1 \mathrm{~atm}, \mathrm{RT}-500{ }^{\circ} \mathrm{C}$ ) of the samples. CO (Air Liquide, 99.997\% purity) was dosed using a stainless steel buffer and electro-valves. The samples were prepared in the form of self-supported pellets (13 $\mathrm{mm}$ diameter, ca. $500 \mathrm{~mm}$ thickness, $c a .20 \mathrm{mg}$ weight), which were pretreated at $350{ }^{\circ} \mathrm{C}\left(5{ }^{\circ} \mathrm{C} \mathrm{min}{ }^{-1}, 1 \mathrm{~h}\right.$ plateau $)$ in $\mathrm{H}_{2}$ flow when needed, and outgassed at $350{ }^{\circ} \mathrm{C}$ for $1 \mathrm{~h}$ under vacuum. Cumulative dosing of CO (1 $\mu$ mol per dose) and subsequent spectrum acquisition were performed until saturation coverage. The spectra were recorded with 128 scans and $4 \mathrm{~cm}^{-1}$ resolution in the 4000-900 $\mathrm{cm}^{-1}$ range.

The hydrogenation of cinnamaldehyde in liquid phase was performed in a stirred autoclave. In a typical experiment, $2 \mathrm{mmol}$ of cinnamaldehyde (99\%) were dissolved into $100 \mathrm{~mL}$ of 2-propanol and purged twice with $\mathrm{N}_{2}$. The catalysts were then introduced into the autoclave before a next $\mathrm{N}_{2}$ purge. The reaction was performed at $50{ }^{\circ} \mathrm{C}$ under 10 bar $\mathrm{H}_{2}$ pressure at a stirring speed of $800 \mathrm{rpm}$, for $7 \mathrm{~h}$. A small amount $(0.3 \mathrm{~mL})$ of the reacting mixture was withdrawn every $30 \mathrm{~min}$ and analyzed by gas chromatography (Varian 3380).

\section{Results and discussion}

\section{Characterization of colloidal suspensions}

Dynamic light scattering. The first goal of our study was to determine the particle sizes and their stability for colloidal suspensions of $\mathrm{Au}, \mathrm{Rh}$ and AuRh (50:50 mol\% target composition) particles stabilized by polyvinyl alcohol (PVA). DLS allows evaluating in situ the hydrodynamic diameter ${ }^{39}$ of asformed colloidal particles and their size evolution as a function of time. As shown in Fig. 1, as soon as the $\mathrm{NaBH}_{4}$ reducing agent is added $(t=0)$, colloids are immediately obtained due to a fast nucleation process. The Au colloids exhibit an initial dynamic size of $6.5 \mathrm{~nm}$ increasing only slightly with time (up to $7.0 \mathrm{~nm}$ after $13 \mathrm{~h}$ in solution). They are therefore quite stable, suggesting that gold NP nucleation is fast, with complete

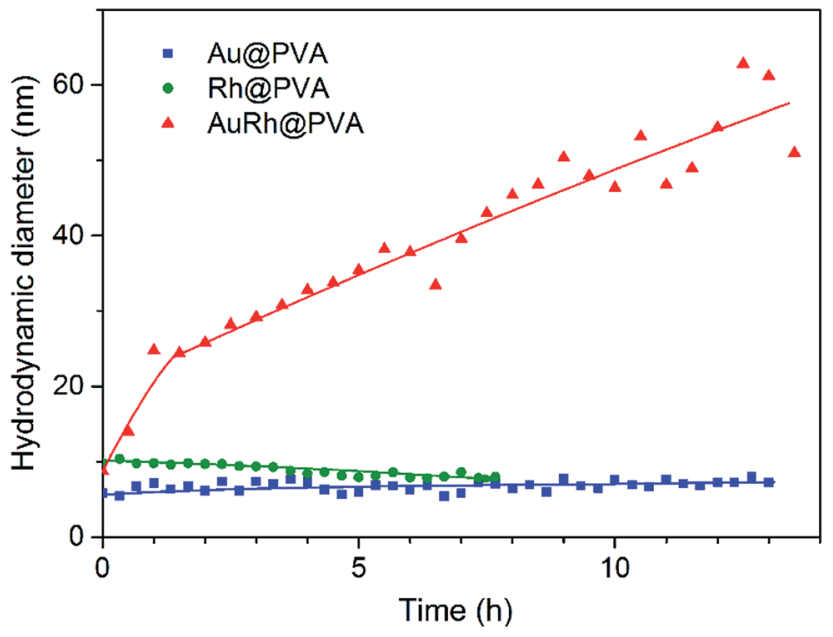

Fig. 1 Evolution of the hydrodynamic diameter (determined by DLS) of PVA-stabilized Au, Rh, and AuRh colloids during their synthesis in solution. consumption of the precursor and no further Ostwald ripening. The size evolution of Rh colloids somewhat differs from that of Au colloids. A slow but continuous decrease in size is observed. The initial size of about $10 \mathrm{~nm}$ gradually decreases down to $8 \mathrm{~nm}$ after $5 \mathrm{~h}$ in solution. This suggests a consumption of Rh NPs by corrosive oxidation. Indeed, the $\mathrm{O}_{2} / \mathrm{Cl}^{-}$mixture (chloride coming from the $\mathrm{Au}$ and $\mathrm{Rh}$ precursors), known to act as an oxidative corroding agent, ${ }^{\mathbf{4 0}}$ is present under our experimental conditions. This likely causes the depletion of $\mathrm{Rh}$ revealed by elemental analysis of the supported catalysts (see below). As compared to the Rh situation, the absence of any corrosive oxidation for the Au NPs indicates a stronger stabilizing effect of PVA and/or a lower reactivity in the Au case. It should be noticed that after $48 \mathrm{~h}$ in solution, no further size evolution of the monometallic colloids can be observed. The AuRh NPs present a rapid growth in size, suggesting a fast aggregation process. Indeed, they exhibit an initial dynamic size of 8-10 nm, while after $10 \mathrm{~h}$ in solution, the average size reaches up to $50 \mathrm{~nm}$. The stability of the bimetallic AuRh colloids is thus strikingly lower than that of the monometallic sols, which can be related to the lack of miscibility between $\mathrm{Au}$ and $\mathrm{Rh}$ and/or an incomplete protecting effect of polyvinyl alcohol (PVA) ligands. Therefore, in the next step of sol immobilization on the $\mathrm{TiO}_{2}$ support, the fresh AuRh sols were used after only $1 \mathrm{~h}$ ageing in order to maintain their final dynamic size below $10 \mathrm{~nm}$.

In situ liquid transmission electron microscopy. The colloidal growth of AuRh NPs was also monitored in situ inside a TEM apparatus enabling their visualization in the liquid phase. Fig. 2a displays the evolution of AuRh NPs in solution during the reduction induced by the electron beam. The nucleation step is fast and the NPs are already visible after 20 seconds of irradiation. The average particle size increases up to $4 \mathrm{~nm}$ (Fig. 2b), consistently with the value determined from $e x$ situ TEM (see below). A previous STEM investigation of unsupported AuRh@PVA colloids has shown that the NPs exhibit roundish shapes and several structural types (single-crystalline, multi-twinned, etc.). ${ }^{34}$ The density of NPs as a function of the irradiation time is reported in Fig. 2c. The number of AuRh NPs first increases rapidly and reaches a plateau after 25 seconds, then it decreases due to the frequent coalescence of NPs in solution, as also directly visible in the image series of Fig. 2a and 3. The growth mechanism corresponds to the direct adsorption of monomers ${ }^{38}$ during $25 \mathrm{~s}$, followed by coalescence and/or Ostwald ripening, which probably result from a partial capping of the metal by PVA, as also observed in situ for Pt NPs. ${ }^{41}$ These processes allow stabilizing the AuRh NPs by reducing their surface energy trough their increase in size. ${ }^{42}$ This result agrees with the DLS measurements, showing the relative instability of AuRh bimetallic sols.

UV-vis spectroscopy. Au, Rh and AuRh sols were also characterized by UV-vis spectroscopy (Fig. 4). The Au NPs exhibit a clear plasmon band at $550 \mathrm{~nm}$ characteristic of spherical particles. ${ }^{43}$ In contrast, the Rh NPs only show a weak but discernible plasmon band in the UV region, with a maximum around $230 \mathrm{~nm}$ and a tail extending from $300 \mathrm{~nm}$ to $900 \mathrm{~nm} .^{\mathbf{4 4}}$ The addition of $\mathrm{Rh}$ to $\mathrm{Au}$ leads to the complete disappearance of the Au plasmon band at $550 \mathrm{~nm}$, while the Rh plasmon can still 

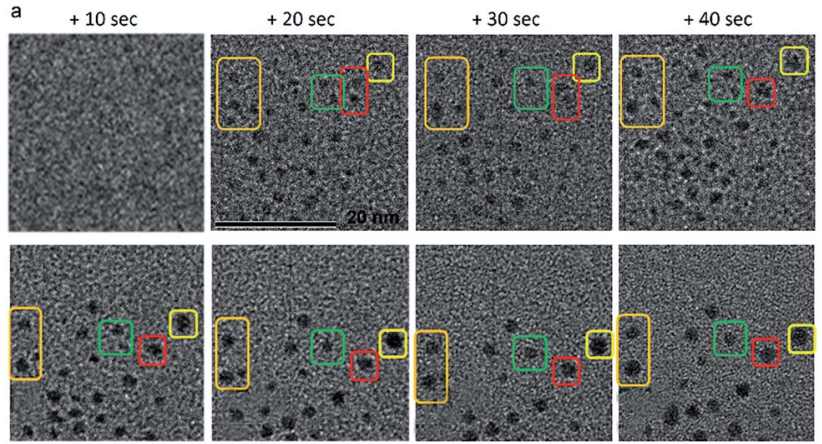

$+60 \mathrm{sec}$

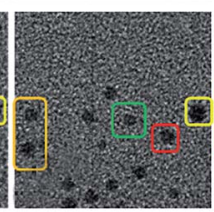

$+70 \mathrm{sec}$

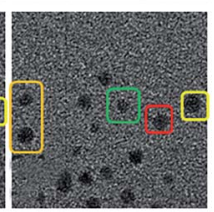

$+80 \mathrm{sec}$
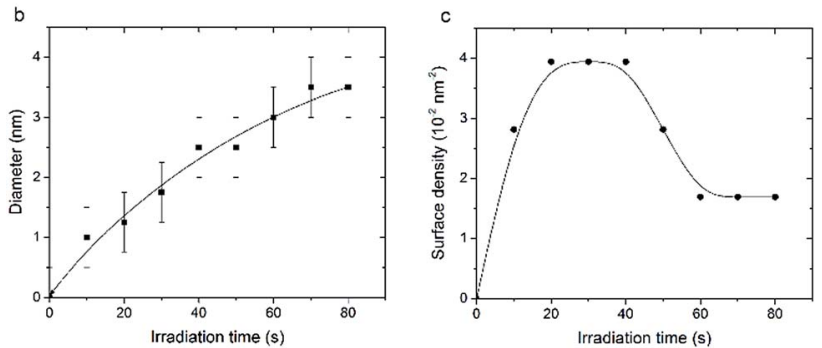

Fig. 2 (a) In situ liquid TEM images showing the nucleation and growth of AuRh nanoalloys in solution during reduction of the precursors by the electron beam. The colored rectangles allow following individual particles. The actual sample size for all images is $30 \times 30 \mathrm{~nm}$. The bottom graphs show the corresponding NP diameter (b) and surface density (c) in the solution as a function of electron irradiation time.
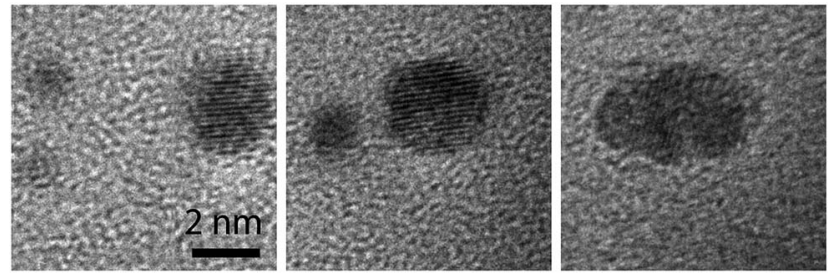

Fig. 3 Successive liquid TEM images showing the gradual coalescence of AuRh NPs in solution (from left to right). The images were recorded with a time interval of $10 \mathrm{~s}$.

be detected around $230 \mathrm{~nm}$. This supports the formation of bimetallic AuRh NPs. Moreover, the detection of the Rh plasmon suggests the formation of Au@Rh core-shell NPs, as claimed by Toshima. ${ }^{45}$ However, post-synthesis STEM observations have shown that several shapes and chemical configurations of AuRh NPs co-exist. ${ }^{34}$

\section{Characterization of supported catalysts}

Elemental analysis. After formation of the metallic NPs in solution, the sols were deposited onto rutile $\mathrm{TiO}_{2}$ nanorods through acid-assisted immobilization using a $0.01 \mathrm{M} \mathrm{HCl}$ solution, as previously reported. ${ }^{3}$ Table 1 gathers the metal loadings, the $\mathrm{Au}: \mathrm{Rh}$ atomic ratios (determined by ICP-OES), and the average NP sizes (TEM) for the $\mathrm{Au}, \mathrm{Rh}$, and AuRh catalysts. As previously mentioned, a slight deficiency in $\mathrm{Rh}$ is systematically observed with respect to the target loadings. This

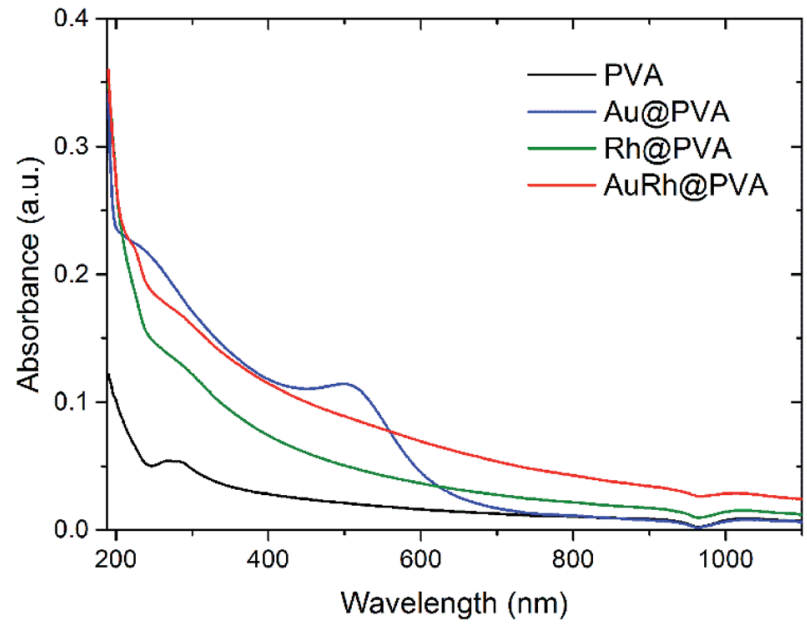

Fig. 4 UV-vis spectra of the Au, Rh, and AuRh sols stabilized by PVA. For comparison purpose, the UV-vis spectrum of PVA alone is also reported (at the same concentration as that used for sols of metallic NPs).

could be related to the partial dissolution (leaching) of $\mathrm{Rh}$ incorporated in the AuRh NPs through the corrosive oxidation already suggested by DLS measurements.

Transmission electron microscopy. As shown in the representative examples of Fig. 5, the catalysts contain small-sized metallic NPs distributed over rutile $\mathrm{TiO}_{2}$ nanorods. In the case of $\mathrm{Au}_{63} \mathrm{Rh}_{37} / \mathrm{TiO}_{2}$, bimetallic NPs, inhomogeneous in shape and often containing single-phase (Au-rich or Rh-rich) domains, coexist with smaller monometallic Rh NPs. ${ }^{3}$ The supported particles appear more facetted than the unsupported ones, and truncated at the interface with the support (due to metal wetting
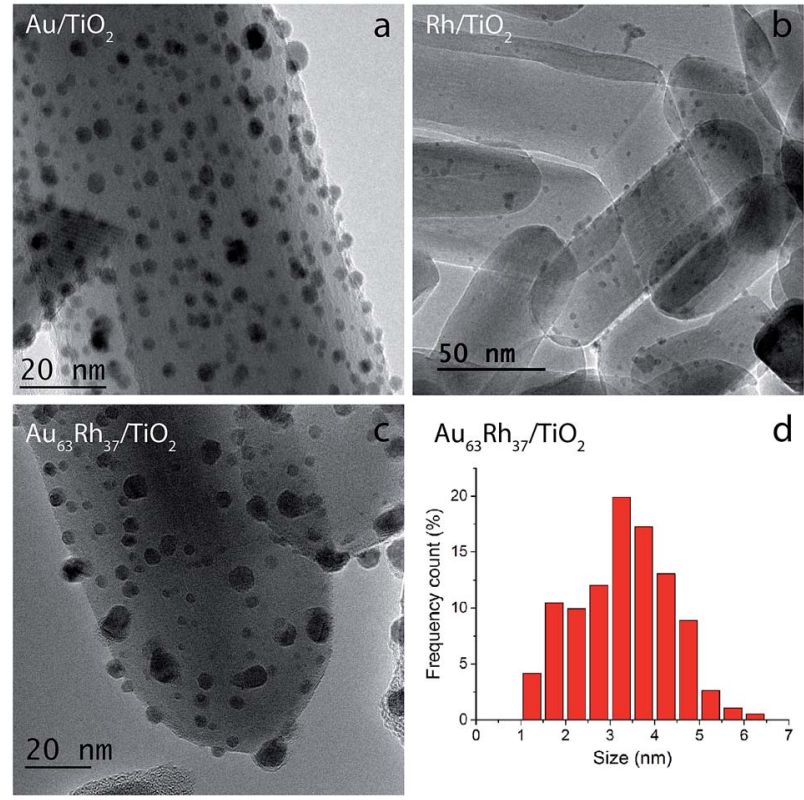

Fig. 5 Representative TEM images of $\mathrm{Au} / \mathrm{TiO}_{2}$ (a), $\mathrm{Rh} / \mathrm{TiO}_{2}$ (b) and $\mathrm{Au}_{63} \mathrm{Rh}_{37} / \mathrm{TiO}_{2}$ (c) as-prepared samples. (d) AuRh particle size distribution for the sample depicted in (c). 
over the support). One should note the importance of the nature of the acid used for the sol immobilization. ${ }^{3,46}$ Using $\mathrm{HCl}$ as in the present case leads to well-dispersed bimetallic NPs, whereas $\mathrm{H}_{2} \mathrm{SO}_{4}$ was found to generate a lower proportion of bimetallic NPs and the presence of sulfur impurities. ${ }^{32}$ The influence of the relative $\mathrm{Au} / \mathrm{Rh}$ molar ratio on the metal particle size in the $\mathrm{AuRh} / \mathrm{TiO}_{2}$ catalysts was also determined by TEM (Table 1). A gradual increase in the particle size with the Au concentration is evidenced, going from $2.4 \mathrm{~nm}$ for $\mathrm{Rh}$ and $\mathrm{Au}_{13} \mathrm{Rh}_{87}$, to $3.2 \mathrm{~nm}$ for $\mathrm{Au}_{37} \mathrm{Rh}_{63}$, and $4.0 \mathrm{~nm}$ for $\mathrm{Au}_{57} \mathrm{Rh}_{43}$. Above 60 at\% $\mathrm{Au}$, the average particle size somewhat decreases to $3.3 \mathrm{~nm}$ for $\mathrm{Au}_{63} \mathrm{Rh}_{37}$, and $2.8 \mathrm{~nm}$ for pure Au. As previously reported, ${ }^{3,34}$ after treatment in $\mathrm{H}_{2}$ flow at $350{ }^{\circ} \mathrm{C}$, the bimetallic NPs keep roughly the same size $(3.7 \pm 1.3 \mathrm{~nm}$ instead of $3.3 \pm 1.0 \mathrm{~nm}$ for the $\mathrm{Au}_{63} \mathrm{Rh}_{37}$ sample) but adopt a Janus configuration with the Rh side contacting the titania support. The (fcc) Au side has a truncated-octahedral morphology, and thus exhibits (111) and (100) facets. $^{34}$

CO-FTIR spectroscopy. $\mathrm{Au}, \mathrm{Rh}$, and AuRh nanocatalysts supported on $\mathrm{TiO}_{2}$, as well as the bare support, were characterized by low-temperature CO adsorption monitored by FTIR
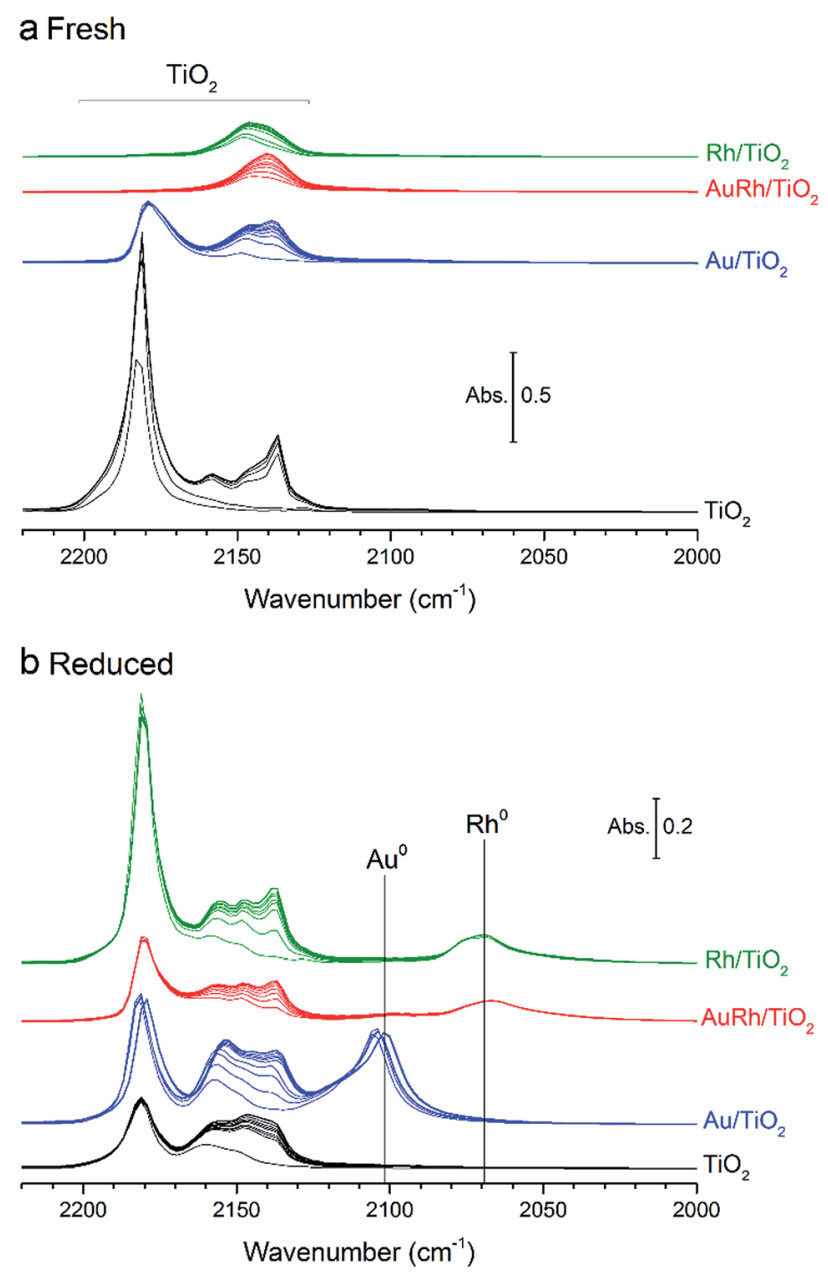

Fig. $6 \mathrm{CO}$-FTIR spectra of $\mathrm{TiO}_{2}, \mathrm{Au} / \mathrm{TiO}_{2}, \mathrm{Rh} / \mathrm{TiO}_{2}$ and $\mathrm{Au}_{63} \mathrm{Rh}_{37} / \mathrm{TiO}_{2}$ as-prepared (a) and in situ pre-reduced (b) catalysts. The spectra were recorded at increasing $\mathrm{CO}$ coverages ( 2 to $42 \mu \mathrm{mol} \mathrm{CO}$ doses). spectroscopy. As shown in Fig. 6, the samples were either analyzed as-prepared ("fresh") or after in situ reduction in $\mathrm{H}_{2}$ flow at $350{ }^{\circ} \mathrm{C}$. In the case of the fresh $\mathrm{TiO}_{2}$ support, a main contribution at $2181 \mathrm{~cm}^{-1}$ due to the chemisorption of CO on $\beta^{\prime \prime} \mathrm{Ti}^{4+}$ Lewis acid sites is present, while the $2158 \mathrm{~cm}^{-1}$ band is related to $\mathrm{CO}$ physisorption on $\mathrm{Ti}-\mathrm{OH}$ sites, and the 2146 and $2137 \mathrm{~cm}^{-1}$ bands correspond to $\mathrm{CO}$ physisorption on $\mathrm{TiO}_{2} \cdot{ }^{47-49}$ The freshly prepared $\mathrm{Au} / \mathrm{TiO}_{2}$ sample presents similar bands, although the proportion of the $\mathrm{CO}-\mathrm{Ti}^{4+}$ chemisorption band is smaller than for bare titania. Finally, fresh $\mathrm{Rh} / \mathrm{TiO}_{2}$ and $\mathrm{AuRh} / \mathrm{TiO}_{2}$ only exhibit $\mathrm{CO}-\mathrm{TiO}_{2}$ physisorption bands. After the reductive treatment, all the bands related to $\mathrm{CO}$ adsorption on titania are present, with the proportion of $\mathrm{CO}-\mathrm{Ti}^{4+}$ increasing in the order: $\mathrm{TiO}_{2}<\mathrm{Au} / \mathrm{TiO}_{2}<\mathrm{AuRh} / \mathrm{TiO}_{2}<\mathrm{Rh} / \mathrm{TiO}_{2}$. Moreover, the bands corresponding to $\mathrm{CO}$ chemisorption on $\mathrm{Au}^{0}\left(2102-2105 \mathrm{~cm}^{-1}\right), \mathrm{Rh}^{0}\left(2069 \mathrm{~cm}^{-1}\right)$, and both $\mathrm{Au}^{0}$ (ca. $\left.2100 \mathrm{~cm}^{-1}\right)$ and $\mathrm{Rh}^{0}\left(2067 \mathrm{~cm}^{-1}\right)^{48-55}$ are observed for the $\mathrm{Au} / \mathrm{TiO}_{2}, \mathrm{Rh} / \mathrm{TiO}_{2}$, and $\mathrm{AuRh} / \mathrm{TiO}_{2}$ catalysts, respectively. However, as the CO-Au contribution is very small in the case of $\mathrm{AuRh} / \mathrm{TiO}_{2}$, Rh may form a thin surface layer surrounding the $\mathrm{Au}$ region of the Janus particles. This would correspond to an
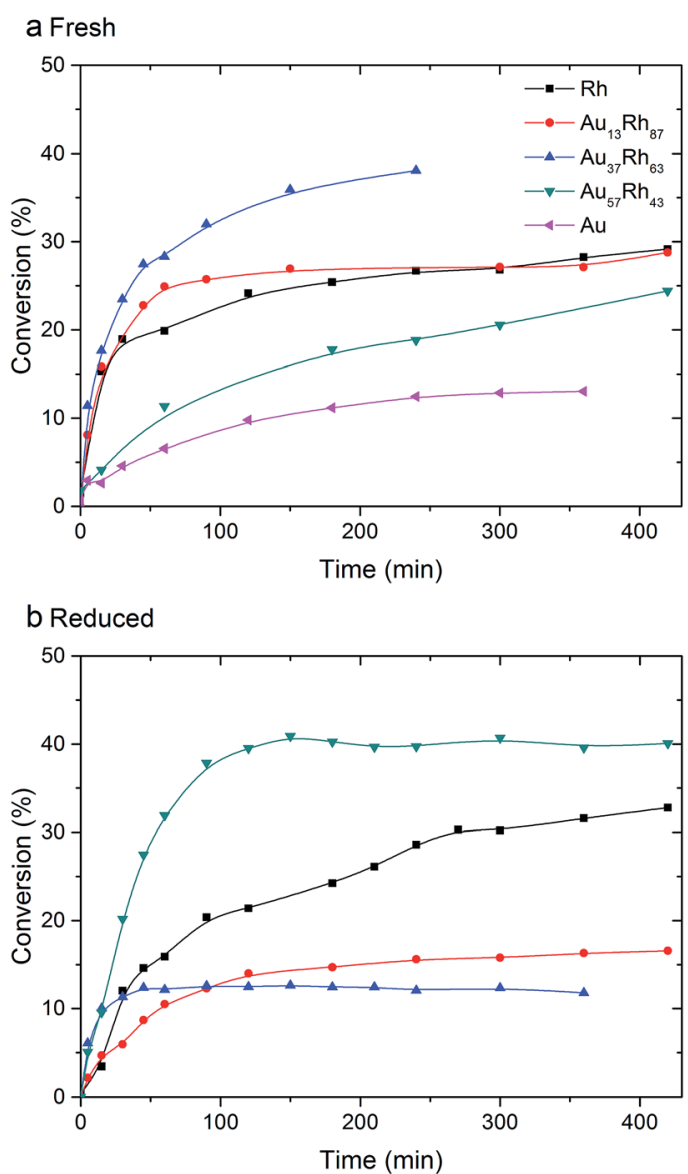

Fig. 7 Evolution of conversions in cinnamaldehyde hydrogenation as a function of the reaction time for fresh (a) and pre-reduced (b) AuRh/ $\mathrm{TiO}_{2}$ catalysts. The reaction was performed at $50{ }^{\circ} \mathrm{C}$ under 10 bar $\mathrm{H}_{2}$ at a stirring speed of $800 \mathrm{rpm}$. 


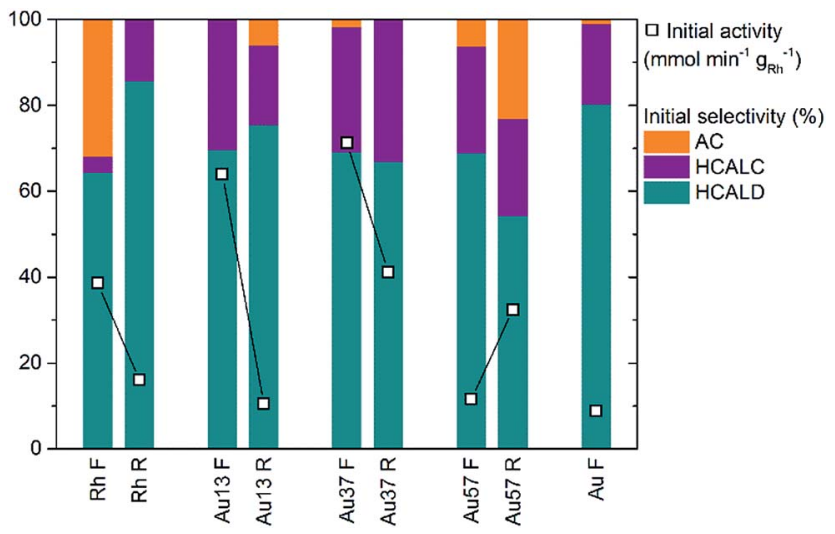

Fig. 8 Initial activities (square dots) and selectivities (bars) in cinnamaldehyde hydrogenation for fresh (F) and pre-reduced (R) $\mathrm{AuRh} / \mathrm{TiO}_{2}$ catalysts. AC, HCALC and HCALD denote hydrocinnamaldehyde diisopropyl acetal, hydrocinnamyl alcohol and hydrocinnamaldehyde, respectively. The initial activity is expressed in mmol min ${ }^{-1} \mathrm{gRh}^{-1}$ except for $\mathrm{Au} / \mathrm{TiO}_{2}\left(\mathrm{mmol} \mathrm{min}^{-1} \mathrm{~g}_{\mathrm{Au}}{ }^{-1}\right)$. Reaction conditions same as Fig. 7 .

off-centered Au core inside a Rh shell, as already observed for, e.g., the $\mathrm{Ag}-\mathrm{Cu}$ system. ${ }^{56}$

\section{Catalytic performances}

Cinnamaldehyde (CALD) hydrogenation was selected as a model reaction to evaluate the catalytic properties of AuRh/ $\mathrm{TiO}_{2}$ systems in comparison to their monometallic counterparts, both as-prepared and after the reductive treatment. The main products detected under our experimental conditions were hydrocinnamaldehyde (HCALD, desired saturated aldehyde) and 3-phenyl-1-propanol, i.e. hydrocinnamyl alcohol (HCALC, undesired saturated alcohol). Cinnamyl alcohol (CALC) was not formed under our experimental conditions. The only (undesired) by-product detected in a non-negligible amount was an acetal (AC) compound, namely hydrocinnamaldehyde diisopropyl acetal, which is formed by reaction of HCALD with the 2-propanol solvent (see below). ${ }^{24}$ The catalysis results are reported in Fig. 7 (conversions vs. time), Fig. 8 (initial activities and selectivities) and Table 2 (numeric data).

Strikingly, the fresh Rh-rich catalysts (Rh molar concentrations of $100 \%, 87 \%$ and $63 \%$ ) appear much more active than their pre-reduced counterparts. This indicates that the presence of PVA at the surface of the particles does not inhibit the reaction, or that the surfactant is removed through in situ washing by the solvent. The initial activities of the fresh catalysts rank in the order: $\mathrm{Au}_{37} \mathrm{Rh}_{63}>\mathrm{Au}_{13} \mathrm{Rh}_{87}>\mathrm{Rh} \gg \mathrm{Au}_{57} \mathrm{Rh}_{43}>\mathrm{Au}$. The most active catalyst, $\mathrm{Au}_{37} \mathrm{Rh}_{63} / \mathrm{TiO}_{2}$, presents an initial activity of $71 \mathrm{mmol} \mathrm{min}^{-1} \mathrm{~g}_{\mathrm{Rh}}{ }^{-1}$ (the activities have been calculated per $\mathrm{Rh}$ weight, except for pure $\mathrm{Au}$, since $\mathrm{Rh}$ is intrinsically much more active than $\mathrm{Au}$ ) and a conversion of $37 \%$ after $3 \mathrm{~h}$ of reaction. The corresponding initial turnover frequency is estimated to 0.57 CALD molecule converted per surface $\mathrm{Rh}$ atom per second, which is close to the values $\left(0.50-0.61 \mathrm{~s}^{-1}\right)$ reported for $\mathrm{Rh} / \mathrm{C}$ catalysts under similar conditions. ${ }^{17}$ After reduction, while all the Rh-rich catalysts are partially deactivated, $\mathrm{Au}_{37} \mathrm{Rh}_{63} / \mathrm{TiO}_{2}$ remains the catalyst with the highest initial activity (41 $\mathrm{mmol} \mathrm{min}^{-1} \mathrm{~g}_{\mathrm{Rh}}{ }^{-1}$ ), but rapidly deactivates. $\mathrm{Au}_{57} \mathrm{Rh}_{43} / \mathrm{TiO}_{2}$ is the only catalyst showing an activation upon reduction, the initial activity changing from 12 to $32 \mathrm{mmol}$ $\min ^{-1} \mathrm{~g}_{\mathrm{Rh}}{ }^{-1}$, and it exhibits the highest final conversion $(40 \%)$.

For the fresh samples, the initial selectivities to HCALD are similar for all the Rh-containing catalysts (64-70\%). Only $\mathrm{Au} /$ $\mathrm{TiO}_{2}$ presents a higher selectivity (80\%) but its activity is quite low. HCALC forms with a very low selectivity on $\mathrm{Rh} / \mathrm{TiO}_{2}(4 \%)$, while higher selectivities are measured for Au-containing catalysts (19-30\%). Interestingly, unlike for the $\mathrm{Rh} / \mathrm{TiO}_{2}$ catalyst, the acetal by-product is initially not or almost not formed on AuRh/ $\mathrm{TiO}_{2}$ catalysts. $\mathrm{Au}_{13} \mathrm{Rh}_{87} / \mathrm{TiO}_{2}$ presents the highest HCALD selectivity at $20 \%$ conversion $(69 \%$, Table 2$)$ and no acetal formation. After reduction, the initial selectivities to HCALD

Table 2 Catalytic performances ${ }^{a}$

\begin{tabular}{|c|c|c|c|c|c|c|c|c|c|}
\hline \multirow[b]{2}{*}{ Catalyst state } & \multirow{2}{*}{$\begin{array}{l}\text { Composition } \\
\text { (at } \% \text { ) }\end{array}$} & \multirow{2}{*}{$\begin{array}{l}\text { Initial activity } \\
\left(\mathrm{mmol} \mathrm{min}^{-1} \mathrm{~g}_{\mathrm{Rh}}{ }^{-1}\right)\end{array}$} & \multicolumn{3}{|c|}{ Initial selectivity (\%) } & \multirow{2}{*}{$\begin{array}{l}\text { Conversion after } \\
3 \mathrm{~h}(\%)\end{array}$} & \multicolumn{3}{|c|}{$\begin{array}{l}\text { Selectivity at } 20 \% \\
\text { conversion }(\%)\end{array}$} \\
\hline & & & HCALD & HCALC & $\mathrm{AC}$ & & HCALD & HCALC & $\mathrm{AC}$ \\
\hline \multirow[t]{5}{*}{ Fresh } & $\mathrm{Rh}$ & 39 & 64 & 4 & 32 & 25 & 61 & 10 & 29 \\
\hline & $\mathrm{Au}_{13} \mathrm{Rh}_{87}$ & 64 & 70 & 30 & 0 & 27 & 69 & 31 & 0 \\
\hline & $\mathrm{Au}_{37} \mathrm{Rh}_{63}$ & 71 & 69 & 29 & 2 & 37 & 64 & 26 & 10 \\
\hline & $\mathrm{Au}_{57} \mathrm{Rh}_{43}$ & 12 & 69 & 25 & 6 & 18 & 52 & 18 & 30 \\
\hline & $\mathrm{Au}$ & 9 & 80 & 19 & 1 & 11 & 48 & 27 & 25 \\
\hline \multirow[t]{4}{*}{ Reduced } & $\mathrm{Rh}$ & 16 & 86 & 14 & 0 & 24 & 69 & 15 & 16 \\
\hline & $\mathrm{Au}_{13} \mathrm{Rh}_{87}$ & 10 & 76 & 18 & 6 & 15 & 61 & 18 & 21 \\
\hline & $\mathrm{Au}_{37} \mathrm{Rh}_{63}$ & 41 & 67 & 33 & 0 & 12 & 69 & 31 & 0 \\
\hline & $\mathrm{Au}_{57} \mathrm{Rh}_{43}$ & 32 & 54 & 23 & 23 & 40 & 35 & 14 & 51 \\
\hline
\end{tabular}

${ }^{a}$ The initial activity is expressed in $\mathrm{mmol} \mathrm{min}^{-1} \mathrm{~g}_{\mathrm{Rh}}{ }^{-1}$ except for $\mathrm{Au} / \mathrm{TiO}_{2}\left(\mathrm{mmol} \mathrm{min}{ }^{-1} \mathrm{~g}_{\mathrm{Au}}{ }^{-1}\right)$, the initial selectivity is defined as the ratio between the rate of formation of a given product and the rate of consumption of the reactant at $t=0$, and the selectivity is defined as the ratio between the concentration of a given product and the concentration of all products. For $\mathrm{Au} / \mathrm{TiO}_{2}$, the results are given only without post-treatment, since otherwise this catalyst presented negligible conversion values. HCALD, HCALC and AC denote hydrocinnamaldehyde, hydrocinnamyl alcohol, and hydrocinnamaldehyde diisopropyl acetal, respectively. The reaction was performed at $50{ }^{\circ} \mathrm{C}$ under $10 \mathrm{bar} \mathrm{H}_{2}$ at a stirring speed of $800 \mathrm{rpm}$. 
decrease with increasing Au loading. Noticeably, the $\mathrm{Rh} / \mathrm{TiO}_{2}$ catalyst no longer presents any initial formation of acetal, contrary to its fresh counterpart. In contrast, the Au-rich $\mathrm{Au}_{57} \mathrm{Rh}_{43} / \mathrm{TiO}_{2}$ sample exhibits a high initial selectivity to acetal (23\%). The best compromise in terms of initial activity and HCALD selectivity is observed for $\mathrm{Au}_{37} \mathrm{Rh}_{63} / \mathrm{TiO}_{2}$, but the final CALD conversion is low (12\%).

In summary, these results clearly show the superior performances of the Rh-rich fresh AuRh catalysts. Two groups of AuRh systems can be defined: up to $\sim 40$ at $\% \mathrm{Au}$, the catalysts exhibit behaviors close to that of $\mathrm{Rh}$ but with enhanced activity and selectivity to HCALD and decreased acetal formation, while increasing the $\mathrm{Au}$ concentration above 50 at\% leads to a loss of the beneficial effect of $\mathrm{Au}$ addition to $\mathrm{Rh}$. Only for $\mathrm{Au}_{57} \mathrm{Rh}_{43} / \mathrm{TiO}_{2}$, the reductive treatment increases the activity, but also favors acetal production.

The formation of by-products in cinnamaldehyde hydrogenation has been extensively reported. ${ }^{57-62}$ They generally result from the reaction of solvents with the hydrocarbon reactant or its hydrogenated, isomerized, or $\mathrm{C}-\mathrm{O}$ hydrogenolyzed products. ${ }^{\mathbf{2 4 , 6 1}}$ Acetals are generally formed when using light alcohols as solvents. However, Rylander and Himelstein have shown that the use of light alcohols is beneficial to the activity. ${ }^{63}$ Acetal formation is also favored by the Lewis acid character of the catalyst. ${ }^{4}$ In our case, CO-FTIR has shown the presence of Lewis acidity on the catalysts. It may be associated not only to the $\mathrm{TiO}_{2}$ support but also to $\mathrm{Rh}^{\delta+}$ sites (i.e., oxidic $\mathrm{Rh}$ species), the amount of which was previously shown to decrease in bimetallics due to $\mathrm{Au}$-induced $\mathrm{Rh}^{0}$ stabilization. ${ }^{3}$ Consistently, for the Rh-rich samples, the benefit of a relatively intimate contact between $\mathrm{Au}$ and $\mathrm{Rh}$ is lost after treatment, due to enhanced metal segregation (Janus NPs). On the opposite, for Au-rich $\mathrm{AuRh}$, the high dilution of $\mathrm{Rh}$ with $\mathrm{Au}$ in fresh catalysts is consistent with a poor hydrogenation ability, while the formation of Janus-type particles upon treatment would make Rh available for participating in the catalytic process. Finally, since the average metal particle size varies in the range $2.4-4.0 \mathrm{~nm}$ (Table 1), some contribution of size and/or morphology effects cannot be excluded, although essentially on the products

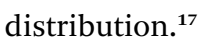

\section{Conclusions}

The growth of AuRh NPs and the influence of the post-treatment on structural and hydrogenation properties of $\mathrm{AuRh} / \mathrm{TiO}{ }_{2}$ catalysts have been studied using a combination of advanced characterization techniques and catalytic testing. Liquid-phase selective hydrogenation of cinnamaldehyde provides an alternative tool for establishing structure-composition-activity relationships.

DLS and liquid TEM experiments enable an in situ monitoring of the nanoparticle ripening and coalescence processes. It was shown that AuRh colloids are much less stable in solution that $\mathrm{Au}$ and Rh colloids, which imposes a thorough control of the preparation parameters for obtaining small AuRh NPs (2-4 $\mathrm{nm})$. In fresh Rh-rich bimetallic catalysts, the intermixing between $\mathrm{Au}$ and $\mathrm{Rh}$ phases favors Au-induced stabilization of $\mathrm{Rh}$ in its metallic form, improving both the activity and the selectivity to hydrocinnamaldehyde with respect to $\mathrm{Rh} / \mathrm{TiO}_{2}$. The reducing treatment at $350{ }^{\circ} \mathrm{C}$, in spite of its ability to remove the PVA surfactant, enhances $\mathrm{Au}-\mathrm{Rh}$ segregation phenomena and thereby cancels the stabilizing effect of $\mathrm{Au}$, leading to lower catalytic efficiency.

\section{Acknowledgements}

We acknowledge the financial support from the French National Research Agency (ANR-BS10-009 "DINAMIC" project). We thank F. Morfin (CO-FTIR), M. Aouine (TEM), and N. Cristin \& P. Mascunan (ICP-OES) for technical support.

\section{References}

1 L. Piccolo, in Nanoalloys: Synthesis, Structure and Properties, ed. D. Alloyeau, C. Mottet and C. Ricolleau, Springer London, 2012, pp. 369-404.

2 G. J. Hutchings and C. J. Kiely, Acc. Chem. Res., 2013, 46, 1759-1772.

3 Z. Konuspayeva, P. Afanasiev, T.-S. Nguyen, L. D. Felice, F. Morfin, N.-T. Nguyen, J. Nelayah, C. Ricolleau, Z. Y. Li, J. Yuan, G. Berhault and L. Piccolo, Phys. Chem. Chem. Phys., 2015, 17, 28112-28120.

4 J. Raskó, Á. Koós, K. Baán and J. Kiss, React. Kinet. Catal. Lett., 2007, 90, 187-195.

5 L. Óvári, L. Bugyi, Z. Majzik, A. Berkó and J. Kiss, J. Phys. Chem. C, 2008, 112, 18011-18016.

6 L. Óvári, A. Berkó, R. Gubó, Á. Rácz and Z. Kónya, J. Phys. Chem. C, 2014, 118, 12340-12352.

7 L. Óvári, A. Berkó, G. Vári, R. Gubó, A. P. Farkas and Z. Kónya, Phys. Chem. Chem. Phys., 2016, 18, 25230-25240.

8 R. L. Chantry, W. Siriwatcharapiboon, S. L. Horswell, A. J. Logsdail, R. L. Johnston and Z. Y. Li, J. Phys. Chem. C, 2012, 116, 10312-10317.

9 R. L. Chantry, I. Atanasov, W. Siriwatcharapiboon, B. P. Khanal, E. R. Zubarev, S. L. Horswell, R. L. Johnston and Z. Y. Li, Nanoscale, 2013, 5, 7452-7457.

10 B. T. Sneed, C.-H. Kuo, C. N. Brodsky and C.-K. Tsung, J. Am. Chem. Soc., 2012, 134, 18417-18426.

11 S. García, L. Zhang, G. W. Piburn, G. Henkelman and S. M. Humphrey, ACS Nano, 2014, 8, 11512-11521.

12 E. R. Essinger-Hileman, D. DeCicco, J. F. Bondi and R. E. Schaak, J. Mater. Chem., 2011, 21, 11599-11604.

13 Y. Shubin, P. Plyusnin, M. Sharafutdinov, E. Makotchenko and S. Korenev, Nanotechnology, 2017, 28, 205302.

14 S. Fleischer, S. Zhou, K. Junge and M. Beller, Angew. Chem., Int. Ed., 2013, 52, 5120-5124.

15 G.-H. Wang, X. Deng, D. Gu, K. Chen, H. Tüysüz, B. Spliethoff, H.-J. Bongard, C. Weidenthaler, W. Schmidt and F. Schüth, Angew. Chem., Int. Ed., 2016, 55, 11101-11105.

16 M. Zhao, K. Yuan, Y. Wang, G. Li, J. Guo, L. Gu, W. Hu, H. Zhao and Z. Tang, Nature, 2016, 539, 76-80.

17 P. Gallezot and D. Richard, Catal. Rev.: Sci. Eng., 1998, 40, 81-126.

18 F. Delbecq and P. Sautet, J. Catal., 1995, 152, 217-236.

19 P. Claus, Top. Catal., 1998, 5, 51-62. 
20 C. J. Kliewer, M. Bieri and G. A. Somorjai, J. Am. Chem. Soc., 2009, 131, 9958-9966.

21 A. Mehri, H. Kochkar, S. Daniele, V. Mendez, A. Ghorbel and G. Berhault, J. Colloid Interface Sci., 2012, 369, 309-316.

22 B. Coq, P. S. Kumbhar, C. Moreau, P. Moreau and M. G. Warawdekar, J. Mol. Catal. A: Chem., 1993, 85, 215-228.

23 M. Englisch, A. Jentys and J. A. Lercher, J. Catal., 1997, 166, 25-35.

24 M. Lashdaf, A. O. I. Krause, M. Lindblad, M. Tiitta and T. Venäläinen, Appl. Catal., A, 2003, 241, 65-75.

25 M. E. Grass, R. M. Rioux and G. A. Somorjai, Catal. Lett., 2009, 128, 1-8.

26 X. Yang, A. Wang, X. Wang, T. Zhang, K. Han and J. Li, J. Phys. Chem. C, 2009, 113, 20918-20926.

27 P. Claus, A. Brückner, C. Mohr and H. Hofmeister, J. Am. Chem. Soc., 2000, 122, 11430-11439.

28 X. Yang, D. Chen, S. Liao, H. Song, Y. Li, Z. Fu and Y. Su, J. Catal., 2012, 291, 36-43.

29 T. Szumełda, A. Drelinkiewicz, R. Kosydar and J. Gurgul, Appl. Catal., A, 2014, 487, 1-15.

30 X. Yuan, J. Zheng, Q. Zhang, S. Li, Y. Yang and J. Gong, AIChE J., 2014, 60, 3300-3311.

31 M. G. Prakash, R. Mahalakshmy, K. R. Krishnamurthy and B. Viswanathan, Catal. Today, 2016, 263, 105-111.

32 Z. Konuspayeva, G. Berhault, P. Afanasiev, T.-S. Nguyen, A. Auyezov, M. Burkitbayev and L. Piccolo, in MRS Proceedings, MRS Online Proceedings Library, 2014, vol. 1641, pp. mrsf13-1641-aa08-07.

33 T.-S. Nguyen, D. Laurenti, P. Afanasiev, Z. Konuspayeva and L. Piccolo, J. Catal., 2016, 344, 136-140.

34 L. Piccolo, Z. Y. Li, I. Demiroglu, F. Moyon, Z. Konuspayeva, G. Berhault, P. Afanasiev, W. Lefebvre, J. Yuan and R. L. Johnston, Sci. Rep., 2016, 6, 35226.

35 I. Demiroglu, Z. Y. Li, L. Piccolo and R. L. Johnston, Catal. Sci. Technol., 2016, 6, 6916-6931.

36 I. Demiroglu, Z. Y. Li, L. Piccolo and R. L. Johnston, Comput. Theor. Chem., 2017, 1107, 142-151.

37 H. Li and P. Afanasiev, Mater. Res. Bull., 2011, 46, 2506-2514. 38 A. De Clercq, W. Dachraoui, O. Margeat, K. Pelzer, C. R. Henry and S. Giorgio, J. Phys. Chem. Lett., 2014, 5, 2126-2130.

39 B. J. Berne and R. Pecora, Dynamic Light Scattering: With Applications to Chemistry, Biology and Physics, Dover Publications, 2000.
40 B. Wiley, T. Herricks, Y. Sun and Y. Xia, Nano Lett., 2004, 4, 1733-1739.

41 J. M. Yuk, J. Park, P. Ercius, K. Kim, D. J. Hellebusch, M. F. Crommie, J. Y. Lee, A. Zettl and A. P. Alivisatos, Science, 2012, 336, 61-64.

42 M. Kahlweit, Adv. Colloid Interface Sci., 1975, 5, 1-35.

43 E. Csapó, A. Oszkó, E. Varga, Á. Juhász, N. Buzás, L. Körösi, A. Majzik and I. Dékány, Colloids Surf., A, 2012, 415, 281-287.

44 M. Pradhan, S. Sarkar, A. K. Sinha, M. Basu and T. Pal, J. Phys. Chem. C, 2010, 114, 16129-16142.

45 N. Toshima, Pure Appl. Chem., 2000, 72, 317-325.

46 Y. Zhao, L. Jia, J. A. Medrano, J. R. H. Ross and L. Lefferts, ACS Catal., 2013, 3, 2341-2352.

47 K. Hadjiivanov, Appl. Surf. Sci., 1998, 135, 331-338.

48 F. Boccuzzi and A. Chiorino, J. Phys. Chem. B, 2000, 104, 5414-5416.

49 H. Klimev, K. Fajerwerg, K. Chakarova, L. Delannoy, C. Louis and K. Hadjiivanov, J. Mater. Sci., 2007, 42, 3299-3306.

50 L. Piccolo, H. Daly, A. Valcarcel and F. C. Meunier, Appl. Catal., B, 2009, 86, 190-195.

51 M. Primet, J. Chem. Soc., Faraday Trans. 1, 1978, 74, 25702580.

52 J. T. Yates, T. M. Duncan, S. D. Worley and R. W. Vaughan, J. Chem. Phys., 1979, 70, 1219-1224.

53 F. Solymosi and M. Pasztor, J. Phys. Chem., 1985, 89, 47894793.

54 L. L. Sheu and W. M. H. Sachtler, J. Mol. Catal., 1993, 81, 267-278.

55 S. Trautmann and M. Baerns, J. Catal., 1994, 150, 335-344.

56 C. Langlois, Z. L. Li, J. Yuan, D. Alloyeau, J. Nelayah, D. Bochicchio, R. Ferrando and C. Ricolleau, Nanoscale, 2012, 4, 3381-3388.

57 J. Šimoník and L. Beránek, J. Catal., 1972, 24, 348-351.

58 H. Noller and W. M. Lin, J. Catal., 1984, 85, 25-30.

59 J. M. Campelo, A. Garcia, D. Luna and J. M. Marinas, J. Catal., 1988, 113, 172-184.

60 M. A. Vannice and B. Sen, J. Catal., 1989, 115, 65-78.

61 C. Milone, M. C. Trapani and S. Galvagno, Appl. Catal., A, 2008, 337, 163-167.

62 J. Shi, R. Nie, P. Chen and Z. Hou, Catal. Commun., 2013, 41, 101-105.

63 P. N. Rylander and N. Himelstein, Engelhard Ind., Tech. Bull., 1964, 4, 131-134. 